\title{
From Toxins to Drugs: Chemistry and Pharmacology of Animal Venom and other Secretions
}

\author{
Andrew G Mtewa*1,2,4, Tamirat Bekele ${ }^{2,3,4}$ and Annu Amanjot ${ }^{2}$ \\ ${ }^{1}$ Department of Chemistry, Malawi University of Science and Technology, Malawi \\ ${ }^{2}$ School of Medicine, Mbarara University of Sci. \& Tech, Uganda \\ ${ }^{3}$ Department of Pharmacy, Ambo University, Ethiopia \\ ${ }^{4}$ Pharm-Biotechnology and Traditional Medicine Center of Excellency, Uganda
}

*Corresponding author: Andrew G Mtewa, Chemistry Department, Malawi Institute of

Received Date: November 22, 2018

Technology, Malawi University of Science and Technology, Malawi.

Published Date: February 22, 2019

\begin{abstract}
Animal secretions are currently proving more than before to be one of the best sources of drugs for current and future health complications. Well managed and optimized, their chemical compounds can as well be used to prevent diseases. Insects, mammals, birds and lizards are some of the animals with bioactive peptides. These bioactives come from skin, saliva, venom, excreta, tissues and other fluids among others sources. Animal secretion uses as drugs have been proven both from history of community use as well as from laboratory benches. Drug development and designing from animals requires in-depth studies of the chemistry and pharmacology of the compounds responsible for bioactivities. Peptides form the largest part of these bioactive secretions. They are naturally unstable, and their handling and storage ways need to be optimized to maintain structure and potency which requires focus as well as adequate capital investment in order to get better drugs for health and disease management. The aim of this work was to present some of the pharmacological uses of chemical secretions and venoms from animals.
\end{abstract}

Keywords: Animal venom; Apitherapy; Drug receptors; Acetylcholine; Envenomation; Nutraceuptides; Drug development

\section{Introduction}

Venoms are toxic chemicals made up of proteins and peptides naturally tailored to act on vital systems of victims or preys, usually injected or sprayed into active biological systems through claws, spines and fangs among others [1] for both defensive and attack purposes. Venom in animals represents traits of adaption in ecosystems full of competition for resources and dominance for survival [2,3]. In terms of defense, animal venom gets bad from irritations to death from envenomation. Wasps, ants, bees, spiders, scorpion, centipede and millipede stings are the most known causes of envenomation in the whole world. However, most deaths from envenomation $(80 \%)$ are from snake bites next to scorpion stings with $15 \%$ of deaths.

Many potentially bioactive molecules can be extracted and synthesized from the huge number of known venomous animals; at least 700 conus species, 1500 scorpion species, 725 snake species and 37000 spider species among others. These venomous animals are found in almost every country but are abundant in the tropical regions.

Venoms present a huge and almost unexplored reservoir of biologically active chemical compounds which have a great potential to cure diseases that are currently not responding to therapies. Animal venom use in folk medicine is well documented. Its use was reported for Ayurveda medicine, western traditional medicine and Chinese folk remedies [4,5]. Venom from insects are also reported to have been in use against diseases as early as 1000 BC in the Greek and Egyptian civilizations as well as in the Korean and Chinese traditional medicines [6,7]. Not much has been reported on scientific research using venoms for modern medicine until around the 1950s when a peptide that potentiated bradykinin was isolated from Bottrop's jararaca, a Brazilian viper to develop Captopril $\AA$, a novel commercial angiotensin I-converting enzyme inhibiting drug used to treat renovascular hypertension [8]. In the 
1980s, Misael Bordier Chivas, a Cuban biologist, was conducting some experiments with toxins from animals from which a new finding came up from scorpion venom which showed reductions in the size of rat and dog tumors [9]. Prialt $₫$ was developed in the 1980s from venom peptides isolated from cone snail [10].

Due to their high specificity, venoms are one of the best promising drug scaffolds of all times [1]. These animal venoms are capable of modulating synapses, generate as well as propagate bioactivity by acting selectively on various ion receptors and channels $[11,12]$. In-depth studies on animal venoms' composition and bioactivity as well as the effects on geography and other environmental factors would provide variable important pharmacological information and leads in the development of newer drugs [1]. This paper aims at putting together some of the known animal venoms that have shown some potential to be developed further into drugs against ailments.

\section{Pharmacology of Venoms}

Different animal venoms have been reported to have potential against diseases in preclinical trials as well as from community uses. The following sections present some of the known pharmacological aspects of venom from various animals.

\section{Pharmacology of Snake Venom}

Apart from proteins and other organic compounds, snake venom comprises inorganic compounds to a lesser extent. Venom from sea snakes, kraits and cobras is neurotoxic and usually leads to death by paralysis from the interruption of the neurotransmission while in rattlesnakes and vipers, the venom is hemovasotoxic effective in destruction of tissues and disturbances in the clotting of blood causing organ or/and tissue swelling [13].

Venom from snakes was reported to have been used for years in folk medicine in the Chinese and the western traditional medicines $[4,14]$. It was also reported to have been used since the 7 th BC in Ayurvedic medicine for arthritis and intestinal ailments as well as for life prolonging purposes [5].

Bothrops jararaca (Jararaca pit viper) is a Brazilian arrowhead viper with peptide inhibitors. They are reported to bind to active ACE sites as good as do natural substrates, a mechanism that is vital in the reduction of blood pressure [15]. This mechanism inhibits angiotensin-converting enzymes. Bothrops jararaca venom promises active drugs against cardiac failure and hypertension. Captopril (CAPOTEN $囚$ ) and Enalapril (CASOTEC $囚$ ) are some of the drugs that have been developed from these inhibitors from the viper.

Echis carinatus (Saw-scaled viper) is a venomous viper very common the dry regions of Africa, Sri Lanka, India, Middle East and Pakistan. Its venom is reported to work in antagonism with fibrinogen biding to the GPIIb/llla receptor. Tirofiban (AGGRASTAT $®$ ) is a drug made from the venom used against acute coronary syndrome.

Sistrurus miliarius (Pigmy rattle snake) is a pit viper very common in Southeastern parts of the United States. From the snake venom, eptifibatide (INTEGRILIN®) was made with activities against coronary disorders. Its mechanism of action is by preventing binding of adhesive ligands including fibrinogen and von wille brand factor to GPIIb/IIIa.

Bothrops atrox (Common lancehead snake) is a snake species most common in the eastern side of the Andes, North of South America. Batroxobin (DEFIBRASE $®$ ) is a drug that was made from the venom of this species. Its basic mechanism of action is cleaving fibrinogen A $\alpha$-chains. The drug is used against deafness, acute cerebral infections and unspecified angina pectoris. Bothrops moojeni (Brazilian lancehead snake) is another species that has venom peptides with the same mechanism of action. This species is common in South America's moist forests. Another drug from B. Atrox is platelet gel (PLATELEX-ACT $®$ ) for topical applications of blood Gasification while B. moojeni has another drug derived from it, Fibrin sealant (VIVOSTAT $®$ ) used as an autologous fibrin sealant in surgical operations. In addition to the two species above, another snake species has been studied and its venom also developed into hem coagulase (REPTILASE $®$ ), a prophylaxis against, and treatment to surgical hemorrhage. Its pharmacological mechanism of action includes fibrinogen A $\alpha$-chain cleaving and the activation of prothrombin and factor $\mathrm{X}$.

Three species of snakes; Gloydius ussuriensis (Ussuri mamaushimviper), Deinagkistrodon acutus (Chinese moccasin snake) and Deinagkistrodon acutus (Siberian pit viper snake) have been extracted of peptides which act like enzymes similar to thrombin. By fibrinogenase, the extracted enzymes work as a prophylaxis and treatment to thromboembolic diseases.

Dendroaspis natriuretic peptides (cenderitide, CD-NP) from Dendroaspis angusteiceps (Eastern green snake), reached the clinical trial phase in 2016. It is used to inhibit the aggregation of platelets and the coagulation cascade. The drug is used to treat congestive cardiac failure.

\section{Wasps}

Wasp venom was reported to be rich in molecules that are neuroactive and can be priceless in the development of new nervous system related drugs [11]. Wasp venom has been reported to be bioactive against Parkinson's and Alzheimer's diseases as well as amyotrophic and multiple sclerosis and epilepsy [11].

\section{Bees}

The use of bee products in the management of diseases or another ailment is called apitherapy. Dose administration can be in the form of ointments, injection of diluted venom, creams, acupuncture and even deliberate bee stinging [16].

Bee venom was reported to have a lot of neuromodulative and protective molecules that can be essential in the development of new drugs for nervous system related ailments [11]. In its crude form, venom from bees has been reported to be bioactive against amyotrophic and multiple sclerosis as well as Parkinson's and Alzheimer's diseases and epilepsy [11]. Crude bee venom is also reported to have molecules that work well against pain and other inflammatory diseases like osteoarthritis and rheumatoid arthritis $[17,18]$. rheumatoid arthritis $[17,18]$. 


\section{Lizards}

Gila monster (Heloderma suspectum) venomous saliva was used to proteins and peptides from which exenatide, a protein, was synthesized [19]. This protein imitates glucagon-like peptide-1 action which is an important homeostasis of glucose usually not enough in diabetes mellitus patients [19].

Some of the pharmaceutical benefits of exenatide includes boosting of the secretion of insulin secretion, reduction of improper glucagon secretion elevations and restores insulin response of phase 1 [19]. Most common adverse events include mild nausea which reduces with time of dosage. BYETTA $₫$ and BYDUREON $₫$ are examples of drugs developed from exenatide, used against type 2 diabetes mellitus.

\section{Anemones}

Stichodactyla helianthus (Sun sea anemone), is a sea anemone very common in the Caribbean islands. Stichodactylatoxin shK (dalazatide, shK-186) from the anemone showed potential activity against lupus, multiple sclerosis, rheumatoid arthritis, psoriatic arthritis and other auto immune diseases by acting as a potassium (Kv1.3) channel antagonist.

Blarina brevicauda (Northern short -tailed shrew) is a venomous mammal very commonly found in the northeastern parts of the North American sub-continent. Its venom, soricidin, was developed into a drug that is used against various cancers including ovarian cancer. It works by Inhibiting TRPV6, a calcium selective transient receptor potential channel.

\section{Scorpions}

Medicinal use of scorpion venom is well documented in folk Chinese and western medicine [4,14]. In more recent years, druglike enzymes have been extracted from scorpions for use against different ailments. Leiurus quinquestriatus (Deathstalker), a yellow scorpion is commonly found in scrubland and deserts of North Africa and parts of the Middle East. Chlorotoxin (BLZ-100®, TM$601 ®$ ), a peptide from the scorpion, has shown potential against brain tumors (glioma) and other nervous system cancers [20] and other peptides have shown potential to regulate insulin, which is a useful mechanism against diabetes. The mechanism of action is by Binding to membrane type 1 matrix metalloproteinase (MMP), CLC$3 \mathrm{Cl}$ - channel in glioma cells and other tumors of neuroectodermal origin among others.

\section{Snails}

Venom from Conus magus, a cone snail was used to develop a synthetic drug, ziconotide (Prialt ${ }^{\circ}$ ) (C102H172N36032S) which is a non-NSAID, non-opoidal and non-local anesthetic drug. It is useful on the characteristics of its $\omega$-conotoxin M-VII-A, a type- $\mathrm{N}$ $\mathrm{Ca} 2+$ channel blocker [1,21]. Ziconotide ameliorates chronic pain, which is usually untreatable though with limited efficacy when administered through the oral or common intravenous routes, commending direct administration into the spine [22].

\section{Leeches}

Hirudo medicinalis (European medicinal leech) is one of the leech species used medicinally besides $H$. verbena, $H$. troctina and
H. orientalis. Some peptides have been developed into drugs from $\mathrm{H}$. medicinalis including; Bivalirudin (ANGIOMAX®), an anticoagulant in percuteneous coronary interventions which works as a direct thrombin inhibitor in a reversible way. Another drug is a lepirudin (REFLUDAN $®$ ), an anticoagulant in thromboembolic diseases working by irreversibly binding to thrombin and desirudin (IPRIVASKI $®)$ used to prevent venous thrombotic occurrences. This is a selective and nearly irreversible thrombin inhibitor.

Calliphora vicina (Blowfly) larvae contains an antimicrobial compound, alloferon, which is used as an antiviral and antitumor agent in some parts of South Korea and Russia [23].

\section{Storage of Venom}

Some basic handling and management of animal venom is outlined in various guidelines [24]. Of importance to note, some venom may precipitate after some time in room temperature. In this condition, they may produce toxic fumes and they need to be immediately be removed from the surrounding and contained securely. Venoms are labile to temperatures. They need to be stored in a cold environment to the orders of less than $-20{ }^{\circ} \mathrm{C}(-4 \mathrm{~F})$ up to a period of one month. It is even better if the venom is lymphorized and kept in cold for a relatively longer period.

\section{Conclusion}

Drug development and designing is a process that requires knowledge of properties of the compounds responsible for bioactivities. There is now evidence that these compounds are also available in animal secretions, most of which are peptides. Peptides are naturally not stable under elevated temperatures, as such, handling and storage ways need to be optimized to maintain structure and potency. In some African countries, there is the use of animal venom and secretions in disease management. However, most details are wrapped in secrecy, thereby losing the passing on of knowledge and skills from generation to generation. If such information were well recorded and managed, Africa would be much richer in drug development from animal venoms and other secretions. The study of drugs from animal venom can well feed into an area of nutraceuptides, where formidable potential drug formulations can be developed in combination with plant based bioactives. This area requires focus as well as investment in order to get better drugs for health and disease management.

\section{Acknowledgement}

None.

\section{Conflict of Interest}

No conflict of interest.

\section{References}

1. Calvete JJ, Sanz L, Angulo Y, Lomonte B, Gutierrez JM (2009) Venomics, venoms, antivenoms. Federation of European Biochemical Societies Letters 583(11): 1736-1743.

2. Fry BG, Vidal N, Norman JA, Vonk FJ, Scheib H, et al. (2006) Early evolution of the venom system in lizards and snakes. Nature 439: 584588.

3. Fry BG, Vidal N, Vander Weerd L, Kochva E, Renijifo C (2009) Evolution and diversification of the toxicofera reptile venom system. J Proteomics 72(2): 127-136. 
4. Koh DCI, Armugam A, Jeyaseelan K (2006) Snake venom components and their applications in biomedicine. Cell Mol Life Sci 63(24): 30303041.

5. Glenn K (2013) Venoms to drugs: translating venom peptides into therapeutics. Australian Biochemist 44(3): 1-4.

6. Bogdanov S (2017) Bee venom: Composition, health, medicine: A review. Peptides 1: 1-20.

7. Adewole AM, Ileke KD, Oluyede PO (2013) Perception and knowledge of bee venom therapy as an alternative treatment for common ailments in southwestern Nigeria. FUTA J Res Sci 9: 235-240.

8. Fernandez JH, Neshich G, Camargo ACM (2004) Using bradykininpotentiating peptide structures to develop new antihypertensive drugs. Genet Mol Res 3(4): 554-563.

9. Schwarcz J (2017) Blue Scorpion Venom for Cancer? In Quebec, McGill University.

10. McIntosh M, Cruz LJ, Hunkapiller MW, Gray WR, Olivera BM (1982) Isolation and structure of a peptide toxin from the marine snail Conus Magus. Arch Biochem Biophys 218(1): 329-334.

11. Silva J, Monge Fuentes V, Gomes F, Lopes K, Dos Anjos L, et al. (2015) Pharmacological Alternatives for the Treatment of Neurodegenerative Disorders: Wasp and Bee Venoms and Their Components as New Neuroactive Tools. Toxins (Basel) 7(8): 3179-3209.

12. Escoubas P, Quinton L, Nicholson GM (2008) Venomics: Unravelling the complexity of animal venoms with mass spectrometry. J Mass Spectrom 43(3): 279-295.

13. Marakova YV, Kryukova EV, Shelukhina IV, Lebedev DS, Andreeva TV, et al. (2018) The first recombinant viper three-finger toxins: Inhibition of muscle and neuronal nicotinic acetycholine receptors. Biochemistry, Biophysics and Moleculear Biology 479(1): 127-130.
14. Harvey AL, Bardley KN, Cochran SA, Rowan EG, Pratt JA, et al. (1998) What can toxins tell us for drug discovery? Toxicon : official journal of the International Society on Toxinology 36(11): 1635-1640.

15. Beeton C (2013) Targets and Therapeutic Properties. In: Handbook of Biologically Active Peptides. Edited by Kesten AJ, $2^{\text {nd }}$ edn: Academic Press, pp. 473-482.

16. Ali MA (2012) Studies on bee venom and its medical uses. Int J Adv Res Technol 1(2): 69-83.

17. Kim HJ, Jeon BS (2014) Is acupuncture efficacious therapy in Parkinson's Disease? J Neurol Sci 341(1-2): 1-7.

18. Lee MS, Pittler MH, Shin BC, Kong JC, Ernst E (2008) Bee venom acupuncture for musculoskeletal pain: A review. J Pain 9(4): 289-297.

19. Triplitt C, Chiquette E (2003) Exenatide: from the Gila monster to the pharmacy. J Am Pharm Association 46(1): 44-52.

20. Soroceanu L, Gillespie Y, Khazaeli MB, Sontheimer H (1998) Use of chlorotoxin for targeting of primary brain tumors. Cancer Research 58(21): 4871-4879.

21. NCBI (2018) PubChem Compound Database. In: CID=16135415 National Center for Biotechnology Information.

22. Mc Givern JG (2007) Ziconotide: a review of ots pharmacology and use in the treatment of pain. Neuropsychiatr Dis Treat 3(1): 69-85.

23. Chernysh S, Kim SI, Bekker G, Pleskach VA, Filatova NA, et al. (2002) Antiviral and antitumor peptides from insects. Proceedings of the National Academy of Sciences, pp. 12628-12632.

24. (2010) WHO: WHO Guidelines for the Production, Control and Regulation of Snake Antivenom Immunoglobulins. WHO Technical Report Series. Edited by Standardization WECoB. Geneva: World Health Organization. 